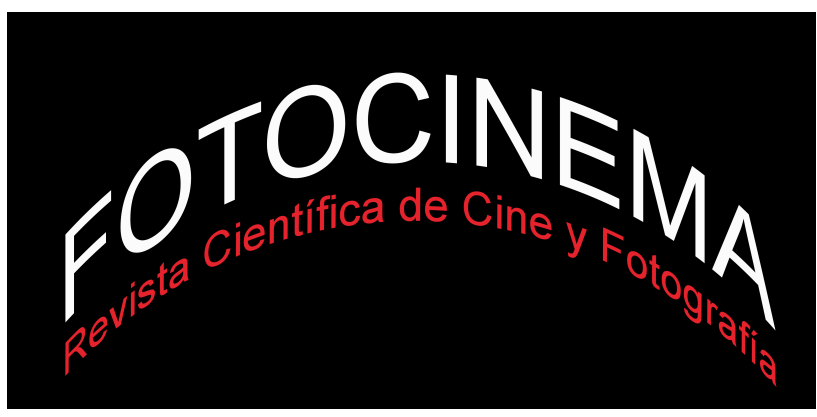

\title{
LES MYSTÈ RES DU CHÂTEAU DU DÉ, REVELADOS POR MAN RAY. EL CINE PINTADO, FOTOGRAFIADO, PENSADO
}

\section{LES MYSTÈRES DU CHÂTEAU DU DÉ, REVEALED BY MAN RAY. THE CINEMA PAINTED, PHOTOGRAPHED, THOUGHT}

Ana Puyol Loscertales

Dra. en Historia del Arte, Universidad de Zaragoza anapl.art@gmail.com

\section{Resumen:}

Les Mystères du château du dé fue el último de los films rodado por Man Ray como encargo particular (de los marqueses de Noailles), bajo ciertas directrices, y con posterior exhibición pública. Más allá de documentar la diversión de la aristocracia en un entorno vanguardista de lujo, es la expresión de toda una propuesta elaborada de pensamiento estético. Es un proceso de exaltación de la unión de la artes proyectado en la gran pantalla, llegando al paroxismo en la generación de un universo independiente del que nos es dado, que no es una imitación, ni un fragmento sustraído de la realidad y dependiente de ella. Man Ray ha creado un espacio para la utopía, y con ello se aproxima a toda una tradición de creadores de mundos alternativos, toda vez que culmina el proyecto regenerador que era el objetivo último del Dadá.

\begin{abstract}
Les Mystères du château du dé was the last of the films directed by Man Ray as a personal request (from the marquess of Noailles), under guidelines and was subsequently shown to the public. Far beyond documenting the fun of the aristocracy in a luxury avant-garde environment, it is the expression of an elaborated purpose of aesthetic thought. It is a process of exaltation of the union of the arts projected on the big screen, reaching the paroxysm in the generation of an independent universe from the one that is given, being neither an imitation nor a fragment taken from reality and dependent of it. Man Ray has created a place for utopia, and so doing he is closer to creators of alternative worlds, and also he culminates the regeneration project that was Dada's main aim.
\end{abstract}

Palabras clave:

Man Ray; Dadá; cine; fotografía; pintura; vanguardias.

Keywords:

Man Ray; Dada; Cinema; Photography; Painting; Avant-garde. 
Cómo citar: Puyol Loscertales, A. (2018). Les Mystères du château du dé, revelados por Man Ray. El cine pintado, fotografiado, pensado. Fotocinema. Revista científica de cine y fotografía, $\mathrm{n}^{0} 16$, pp. 51-77.

Disponible: http://www.revistas.uma.es/index.php/fotocinema/

DOI: http://dx.doi.org/10.24310/Fotocinema.2017.voi15

Este guión no tiene porqué ser una historia coherente pero debe proporcionar un marco para los efectos ópticos o plásticos originales, y yo tendría la responsabilidad de la puesta en escena y de la ejecución. ${ }^{1}$ (Bouhours, 1981, p. 103)

\section{Introducción. El cine como programa estético. La obra de arte como imagen óptica}

Les Mystères du château du dé (1929) ${ }^{2}$ fue el cuarto proyecto cinematográfico unipersonal acometido por el versátil Man Ray. Fue su empresa más ambiciosa y supuso una especie de in crescendo dentro de su producción, no sólo por su mayor complejidad técnica ${ }^{3}$, sino por la abundancia conceptual que acoge, reflejando la riqueza del discurso de su realizador, su lenguaje consolidado.

Jacques-André Boiffard, quien fuera su asistente-operador, comentó: "...creo que la película va a tener grandes fotos provenientes del talento de Man Ray, pero estoy menos seguro de la calidad de la película, cuyo guión y la interpretación parecen un poco abracadabrantes" (Bouhours, 1981, p. 89) 4 Esta aseveración, que concuerda con la cita de Man Ray incluida más arriba, retrata la concepción del cine del americano, donde la ausencia de guión y de

\footnotetext{
${ }^{1}$ Carta enviada a Charles de Noailles, el 24 de noviembre de 1928. [Ce scénario n'a pas forcément besoin d'être une histoire cohérente mais il doit offrir un cadre pour des effets optiques ou plastiques originaux, et j'aurai la charge intégrale de la mise en scène et de la réalisation.]

${ }^{2}$ Aconsejamos acompañar la lectura de este artículo con el visionado de la película, accesible en la red: https://www.youtube.com/watch?v=V6bSygUuU9o

3 "Les Mystères du château du dé", fue rodada en $35 \mathrm{~mm}$, en blanco y negro con filtros de color, dura 26' 31", contó con casi una docena de intérpretes y gozo de una mayor reflexión previa -pues no podemos hablar de planificación al uso-, en cuanto a temática, aspectos dramáticos y puesta en escena.

4 [...je pense que le film aura des très belles photos provenant du talent de Man Ray, mais je suis moins sûr de la qualité du film, dont le scénario et le jeu me semblent un peu abracadabrants.]
} 
narración al uso ${ }^{5}$ se superaba con el establecimiento de una estructura que sirve de soporte para el imaginario y las técnicas que dan forma al pensamiento estético de su creador, muchas veces ajenos al contexto fílmico e introducidos desde el ámbito de la fotografía ${ }^{6}$ o las artes plásticas. Sus realizaciones para el cine se convirtieron en un escenario ideal para la manifestación en la cuarta dimensión, dimensión intelectual, de algunas de sus obras preexistentes, de manera que sus lienzos, aerografías, objetos, pruebas fotográficas o fotogramas, desvelaron una nueva faceta a través de su registro visual y su posterior manifestación mediante la cámara de proyección, convirtiéndose en una imagen óptica, aprehensible por un procedimiento mental, no retiniano.

En definitiva, la producción del americano para el cine fue el marco excepcional para su reflexión en torno a la naturaleza intelectual de la obra creativa; de ahí que sus películas sean la emanación, llena de matices, de su filosofía y su personal teoría del arte.

\section{2- Man Ray y Robert Mallet-Stevens. Técnica, arquitectura y cine}

El Vizconde Charles de Noailles fue el productor del film, rodado cerca de Hyères (Provence-Alpes-Côte d'Azur) en la lujosa vivienda de éste y de su esposa Marie-Laure. El estreno se celebró en privado, el primero de mayo de 1929, en la primera sala doméstica de proyección de cine del país, sita en la mansión parisina de los Noailles ${ }^{7}$, grandes impulsores de las artes ${ }^{8}$.

\footnotetext{
5 En el caso de sus piezas anteriores para el cine, las realizadas por su iniciativa, Le Retour à la raison (1923), Emak Bakia (1926) y L'Étoile de mer (1928), no existe guión, ni siquiera en el último caso, donde el detonante fue un poema de Robert Desnos. Man Ray no se interesó por un cine narrativo, ni realizó adaptaciones de textos, a pesar de la huella inefable de la literatura en su cine y en su plástica. En el caso de Les Mystères du château du dé, se alude a un guión del que no existe evidencia material, aunque sí abundante correspondencia con especificaciones relativas al film.

${ }^{6}$ Le retour à la raison (1923), su primer film en solitario, incluye fotogramas tratados como si fuesen negativos fotográficos, que quiebran la propia división de la película y alteran su naturaleza. Esto incide en la doble lectura de la pieza, en su naturaleza móvil, proyectada, y en su valor material, como película física tratada mediante procedimientos artísticos.

7 El salón parisino de los Noailles, en el número 11 de la Place des États Unis, fue uno de los más célebres para la reunión de intelectuales y de la alta sociedad de París, amén de constituir una referencia en la historia del gusto, por acción del decorador de interiores, Jean-Michel Frank.
} 
A pesar de contar con Henri d’Ursel ${ }^{9}$ entre los invitados al rodaje, los mecenas recurrieron a Man Ray, quien ya había retratado en repetidas ocasiones a los Noailles y había documentado sus eventos. Al respecto del encargo, el americano, cuyo proceso de apropiación del cine se dio desde su identidad como artista plástico, relató:

En el fondo el cine no me interesaba, yo no tenía ningún deseo de convertirme en un realizador de éxito. No me habría sentido tentado para hacer una nueva película si no hubiera dispuesto de fondos ilimitados para tirar por la ventana. ${ }^{10}$ (Man Ray, 1998, p. 364)

En este proyecto, el realizador se rodeó de lo más granado de la alta sociedad asentada en París, parte del círculo de amistades de los Noailles, y miembros de la aristocracia como el Conde Étienne de Beaumont o Lily Pastré, todos reputados promotores del arte, que completaron el reparto de improvisados actores $^{11}$.

La morada donde los Noailles vivían en Saint Bernard, era una obra reciente del arquitecto y escenógrafo Robert Mallet-Stevens, levantada en la segunda mitad del año 1923 sobre las ruinas de una abadía cisterciense, regalo de bodas de la madre del Vizconde. La construcción se proyectó como un alegato por una nueva arquitectura, realizada en cemento, en estilo cubista, según una planificación más afín al ámbito fabril que al doméstico, e

${ }^{8}$ El estreno fue seguido de otro pase privado, el doce de junio de 1929, en el Studio des Ursulines de la capital francesa, acompañado de Un Chien andalou (1929), de Luis Buñuel, sesiones a las que más adelante siguieron algunas proyecciones públicas en este mismo cine del distrito de Val-de-Grâce.

Los Noailles también fueron promotores de L'Âge d'Or (1930), de Luis Buñuel, y Le Sang d'un poète (1930), de Jean Cocteau. En 1928, el Vizconde ya había recurrido a Cinégraphic, sociedad dirigida por Marcel L'Herbier, para realizar un film de cincuenta minutos en la Villa Noailles, dirigido por Jacques Manuel, titulado Biceps et bijoux (1928), por el énfasis con el cual se trata el ejercicio físico en la cinta y por la trama, que gira en torno al robo de unas joyas. El acaudalado aristócrata siempre apreció el potencial escenográfico de su morada, relacionando así la arquitectura con el cine.

9 D'Ursel fue un realizador belga ligado al Surrealismo, que ese mismo año dirigió La Perle (La Perla), película basada en una historia de Georges Hugnet.

10 [Au fond le cinéma ne m'intéressait pas: je n'avais aucune envie de devenir un réalisateur à succès. Je n'aurais été tenté de faire un nouveau film que si j'avais eu des fonds illimités à jeter par la fenêtre.]

${ }^{11}$ El reparto completo aglutinó a Marie-Laure y Charles de Noailles, Alice de Montgomery, Eveline Orlowska, Bernard Deshoulières, Marcel Raval, Lily Pastré, Étienne de Beaumont, Henri d'Ursel y su mujer. Los actores recibieron de sus anfitriones la suma de quinientos francos franceses por su colaboración, lo que testimonia la generosidad de los Noailles y su concepto profesional del encargo. 
incorporando los últimos avances técnicos encaminados a incrementar el confort $^{12}$. Esta visión novedosa se relacionaba con el trabajo de MalletStevens como decorador y arquitecto en el ámbito del cine, pues a él se atribuyen varios diseños que aparecen en L'Inhumaine (1923) de Marcel L’Herbier, que vinculaban su filosofía de trabajo con la estética de las máquinas $^{13}$. Man Ray, en su papel nuclear dentro del Dadá primigenio desarrollado en Nueva York, fue uno de los artistas pioneros en reflexionar en torno al papel de la máquina en la vida y en la incorporación de la misma en un contexto creativo que dilataba sus límites.

La casa contaba con catorce relojes idénticos de la Maison Paul Blot-Garnier repartidos por las habitaciones, sincronizados por un regulador eléctrico central, lo que debió crear un efecto similar al toque de campanas que ordenaba la vida en el antiguo monasterio o, en su versión moderna, a una factoría, con sus actividades reguladas según una concepción del tiempo universal. En este aspecto, destaca que:

....los Noailles afirman que pertenecen a la era de la máquina por un exceso de dispositivos técnicos (sala al aire libre de Chareau, mecanización de la piscina). Por referencia a los trenes, aviones y barcos, varios instrumentos de medición se añaden a estos dispositivos, higrómetro y barómetro, astrolabio y sextante que la ausencia de necesidad transforma su nivel en aparatos sencillos, jalones de una modernización costosa. La vida de castillo en la Villa Noailles toma el aspecto de vida a bordo de un buque. ${ }^{14}$ (Briolle \& Fuzibet \& Monnier, 1999, p. 91)

Esa similitud de la mansión con un buque no resulta extraña para una época donde éste era un emblema del progreso de la ingeniería en el transporte por

12 Mallet-Stevens decretó la destrucción de sus archivos a su muerte, de ahí que la documentación contenida en las monografías dedicadas a su obra sean esenciales a la hora de analizar la trascendencia de esta villa en el panorama arquitectónico del país.

13 La introducción de la máquina se identificaba con los principios de De Stijl en la geometría y los efectos sorprendentes de luces, sombras y volúmenes en los trabajos de este arquitecto. 14 [...les Noailles affirment leur appartenance à l'ère de la machine par une surabondance de dispositifs techniques (chambre en plein air de Chareau, mécanisation poussée de la piscine). Par référence aux trains, avions et paquebots, divers instruments de mesure s'ajoutent à ces appareillages, hygromètre et baromètre, astrolabe et sextant que l'absence de nécessité ramène au niveau de simples gadgets, jalons d'une modernisation coûteuse, la vie de château à la ville Noailles prend des allures de vie à bord d'un navire.]

El especialista Jean-Michel Bouhours, ha evidenciado en este film la confluencia de todo un elenco de machines célibataires, algunas de las cuales se citan en el párrafo anterior. 
agua, aplicando la velocidad a la vida, alterando la percepción espaciotemporal y de los límites y fronteras ${ }^{15}$.

No sólo en la introducción de los criterios mecánicos y la figura de la máquina estaban vinculados los proyectos de ambos vanguardistas, Man Ray y Mallet-Stevens. En el trabajo de este último estaba latente un planteamiento cinematográfico aplicado a la construcción de espacios mediante el volumen, en la línea planteada por el teórico del cine Ricciotto Canudo, que él mismo expuso en su obra teórica:

L'architecture moderne est essentiellement photogénique: grands plans, lignes droites, sobriété d'ornements, surfaces unies, oppositions nettes d'ombres et de lumière; quel meilleur fond peut-on rêver pour les images en mouvement, quelle meilleure opposition pour mettre en relief la vie?.16 (Mallet-Stevens, 1996, p. 52)

El concepto de la arquitectura como entidad fotogénica, enlaza con la construcción de imágenes mediante la luz que Man Ray investigaba como fotógrafo y cineasta, en orden a establecer su programa estético en torno a la generación de la imagen.

En este film, la edificación ostenta un papel protagonista ${ }^{17}$. De hecho la película se estructura en torno a la vivienda según un principio de collage, donde el rodaje aporta cierta unidad, poética, a la mansión concebida como un gran mecanismo, según el cual:

El espacio, denominador común del cine y la arquitectura, puede tomar forma una vez ha sido investido por los acontecimientos que en él se desarrollan, también el arquitecto se pone a cortar, fragmentar, encuadrar, hacer un montaje como el cineasta. ${ }^{18}$ (Vaillant, 1995, p. 101)

\footnotetext{
15 La literatura se hizo amplio eco de estos avances de la ciencia, como es el caso de Alfred Jarry, un autor de referencia para Man Ray, cuyo Doctor Faustroll recorría París en un bateau-crible (barco-tamiz).

16 [L'architecture moderne est essentiellement photogénique: grands plans, lignes droites, sobriété d'ornements, surfaces unies, oppositions nettes d'ombres et de lumière; quel meilleur fond peut-on rêver pour les images en mouvement, quelle meilleure opposition pour mettre en relief la vie?]

17 Hasta la mitad del metraje, la construcción es la protagonista absoluta de la cinta. Con excepción de la obertura del film, donde aparecen los viajeros que emprenden el viaje, sin embargo los actores no hacen su aparición en pantalla hasta llegar al ecuador de la obra.

18 [L'espace, dénominateur commun du cinéma et de l'architecture, ne peut prendre forme
} 


\section{De la imagen a la palabra a través del cine}

Después del título del film, Man Ray incluyó en un fotograma una dedicatoria donde expresa su agradecimiento a Marie-Laure: "A la Vizcondesa de Noailles, le dedico estas imágenes que no desvelarán nunca, idesafortunadamente! toda su gentileza y encanto. MAN RAY"19. Estas palabras revelan la filosofía del realizador en torno al cine, concebido desde su esencia como conjunto móvil de imágenes, de fotogramas. Este posicionamiento cobra sentido desde su dedicación artística original, que había de culminar en el cine como mecanismo capaz de aportar dinamismo a sus obras preexistentes, en soportes estáticos, y de ubicarlas en la cuarta dimensión, convertirlas en imágenes ópticas.

Este film fue ideado por el artista a partir de una fotografía de la mansión que Charles de Noailles le envió y que sirvió como detonante: "Las formas cúbicas del castillo me hicieron pensar en el título de un poema de Mallarmé: 'Una tirada de dados jamás abolirá el azar'. Este sería el tema de la película y su título también: 'Los Misterios del castillo del Dado"20 (Man Ray, 1995, p. 364). Esta referencia conecta con su trascendental etapa formativa americana, concretamente con las lecturas en francés que su primera esposa, Adon Lacroix, realizó para él durante su etapa de convivencia ${ }^{21}$. Entre esas lecturas figuraba la obra del simbolista francés Stéphane Mallarmé, autor de Un coup de dés jamais n'abolira le hasard (1897), que sirvió de estímulo para esta incursión cinematográfica.

Como gran parte de la obra de Mallarmé, ésta es una reflexión acerca de la naturaleza de la poesía y de su capacidad creativa pues, según el literato: "el lenguaje estaba dotado de un misterio que aumentaba con el número de

qu'une fois investi par les événements qui s'y déroulent, aussi l'architecte se met-il à découper, morceler, cadrer, opérer un montage comme le cinéaste.]

19 [À la Vicomtesse de Noailles, je dédie ces images qui ne dévoileront jamais, hélas! toute sa gentillesse ni son charme. MAN RAY] Se alude a la versión de este film que se encuentra en el Departamento de archivos cinematográficos del MNAM Centre Georges Pompidou.

${ }^{20}$ [Les formes cubiques du château me firent penser au titre d'un poème de Mallarmé: 'Un coup de dés jamais n'abolira le hasard'. Ce serait le thème du film, et son titre aussi: 'Les Mystères du château du Dé.]

${ }^{21}$ Man Ray y Adon Lacroix se conocieron en agosto de 1913 en la colonia artística anarquista de Ridgefield (Nueva Jersey), donde se casaron en mayo de 1914 y donde vivieron hasta diciembre de 1915, en que se mudaron a Nueva York, separándose en 1918. El artista aseveró que fue la mujer más importante de su vida. 
direcciones diferentes en que una palabra podía apuntar" (Shattuck, 1991, p. 44), el mismo misterio y capacidad de emanación creativa que Man Ray aportaba a la imagen. Mallarmé devolvió a la palabra la magia de poder ser cualquier cosa en el espacio reservado a lo silencios, dejando lugar para las irradiaciones del lenguaje en lo conceptual y también en lo material, algo patente en la distribución de las palabras y las zonas en blanco sobre el papel y en la ruptura de la sintaxis convencional. De igual manera, Jarry amplió el poder de la palabra hasta que cualquier significación se hacía posible y legítima, igual que los artistas del núcleo del primer Dadá lograron con la técnica y con su primera nacida, la máquina. Si bien, Mallarmé pretendió escapar del azar para abrazar el absoluto, y Jarry acogió el azar para trascender el absoluto en lo posible, que es la línea que mantuvo Man Ray.

El lenguaje, como una máquina, es un conjunto con partes intercambiables, como apuntó Lewis Mumford en relación con el enfoque técnico de la palabra: "Todavía no se ha inventado ninguna máquina tan compleja que se aproxime a la uniformidad, variedad, adaptabilidad y eficiencia del lenguaje" (Mumford, 1969, p. 124). Las vanguardias artísticas, y muy especialmente el Dadá, reflexionaron profundamente sobre este presupuesto en sus manifiestos e ingenios.

Tanto en el poema del simbolista francés como en el poema hecho cine de Man Ray, destaca el juego tipográfico, tan familiar para el americano a raíz de su trabajo de juventud en McGraw-Hill Book Company y por su propia práctica poética. La asimilación del texto implica una lectura lineal y otra de superficie, muy similar al proceso de percepción de imágenes connatural al cine. Consecuentemente, ambos creadores apelaron al desencadenamiento de imágenes como un proceso mental en el receptor, quien culminaría la obra aportando su visión personal, lo que hace de cada pieza una realidad tan múltiple como sus interpretaciones ${ }^{22}$.

Los puntos en común entre el influyente poema de Mallarmé y el discurso de Man Ray, o Duchamp, como adalides del primer Dadá, son evidentes. Todo 
pensamiento emite una tirada de dados, uniendo azar y conocimiento, pensamiento matemático y deriva lingüística, la ciencia y sus posibilidades infinitas, en una crítica a la razón unívoca. El lanzamiento de los dados produce una figura similar al proceso del pensamiento, primero existe un estímulo, al que sigue una acción variable, un proceso circular igual al del raciocinio, que se manifiesta en el rodar de los dados que culmina en un resultado aleatorio. Este proceso es paralelo al desencadenamiento insistente del movimiento circular en las realizaciones de Duchamp, o en el giro mecánico de la cámara de cine en Man Ray, siendo una manifestación del acto de pensar, que es crear.

\section{Un escenario para la confluencia de las artes}

El castillo como escenario del rodaje posee connotaciones significativas, pues alude a un tiempo pasado que se une al presente mediante la construcción superpuesta a la ruina ${ }^{23}$ y abre a un futuro mediante esas ventanas al horizonte cambiante que se observan en la moderna muralla del jardín de la edificación. Son espacios para la emanación, para que el aura de la poesía pueda tener libre curso. La unión de los tres tiempos en el castillo, hace de él un signo poético, que trasciende la sujeción temporal para convertirse en un proceso eterno, según la retórica de Alfred Jarry o del lenguaje suspendido de Mallarmé, que Man Ray manifestó aquí cinematográficamente, uniendo la poesía y la plástica en movimiento.

El realizador sacó partido del castillo para aportar cierto misterio desde la introducción del film, donde ambos, director y asistente, son los protagonistas de una suerte de road movie donde filman su propio viaje. En lugar de citar su función según el argot técnico, Man Ray y Boiffard firman como Les voyageurs (los viajeros), originando una indistinción que se incrementa porque, tanto ellos como el reparto del film, llevan sus cabezas

\footnotetext{
$23 \mathrm{El}$ primero de los intertítulos reza: "Comment deux voyageurs arrivèrent Saint-Bernard, et ce qu'ils virent dans les ruines d'un vieux château, au-dessus lesquelles s'élève un autre château de notre époque. Les voyageurs: Man Ray, J.-A. Boiffard" [Cómo dos viajeros llegaron a Saint-Bernard, y lo que vieron en las ruinas de un viejo castillo de nuestra época. Los viajeros: Man Ray y J.-A. Boiffard].
} 
cubiertas por medias, un camuflaje que niega sus identidades, las cosifica y desaparece cualquier identificación emocional con el espectador, convirtiéndose en impersonales autómatas. José Louis Téllez observa, a este respecto, la abolición de la posibilidad de raccord, que anula a su vez la continuidad fílmica y la narración - que Man Ray boicotea constantemente -, ya que se rompe el juego de relaciones por medio de la mirada, por tanto no hay identificación con el espectador. En conclusión, no hay puntos de vista subjetivos, por lo que todo se convierte en un relato exterior, como introducirse de lleno en una novela de anticipación, una utopía donde se percibe un universo completamente distinto al nuestro.

La parte de la película dedicada al viaje contiene imágenes de gran fuerza plástica, destilada desde la familiaridad de Man Ray en el manejo de luces y sombras, blancos y negros, vinculados con su faceta como fotógrafo, magistral a la hora de generar múltiples efectos. La primera pieza del acompañamiento musical es Gymnopédie $n^{o} 1^{24}$, de su amigo Erik Satie, que suena mientras en la oscuridad de la pantalla se ven dos puntos de luz paralelos aproximarse, dibujando un desplazamiento constante en un espacio abstracto, que finalmente se identifican con los faros del Avions Voisin C11 del americano. El vaivén de la cámara derivado del traqueteo del coche, la rotación sobre su eje, o el rodaje casi a ras de suelo, fueron recursos utilizados por Man Ray para introducir nuevas perspectivas. De este modo produjo esa sensación de extrañeza, de accidente, que acompaña las imágenes en movimiento de los hitos del desarrollo técnico del momento, desde el tren circulando veloz, a las altas chimeneas de las fábricas, los postes telegráficos presentes en los paisajes de todo el país, o un puente volado. Además del recurso a estos emblemas del progreso industrial, técnico, de potente impacto en la estética, la escena del viaje incluye el juego producido por las sombras de los árboles deshojados dibujándose sobre la parte trasera

24 Man Ray dio un gran valor a las piezas musicales que acompañan y complementan su filmografía.

Erik Satie hablaba inglés, y fue uno de los primeros contactos de Man Ray cuando llegó a París, en 1921. El americano, gran melómano, debió conocer los matices que contiene esta melodía, cuyo título alude a una danza griega clásica que los jóvenes de Esparta bailaban desnudos en el seno de una cultura donde el entrenamiento físico era rutinario y se practicaba en desnudez. La censura no permitiría tal imagen en el cine, pero sí la danza luminosa proyectada por las luces de un auto. 
de un camión, proyectadas en él cual sombras chinescas, como si de una pantalla de cine se tratara, donde la realidad genera e imprime su huella por sí misma, convertida en imagen óptica por efecto del cine, que se desliza dentro del cine.

En la obertura no podía faltar una alusión literaria al poema Un coup de dés jamais n'abolira le hasard, de Stéphane Mallarmé, con un gesto de lanzamiento de dados, que sirve a lo largo de la cinta como materialización del proceso de pensamiento. La primera y la última tirada, son ejecutadas por medio de una mano de madera articulada, que marca la dinámica de una acción determinada por una lógica completamente ajena a la usual, por el azar, que es el elemento que estructura la película como reflejo de ese universo alternativo donde tiene lugar la acción ${ }^{25}$.

Esta realización está marcada por la presencia de obras y referencias al orbe artístico y al universo técnico, como era natural en unos coleccionistas de arte como los Noailles que, además, eran portaestandartes de la modernidad en Francia. Ambos registros, arte y técnica, se dan la mano en el pensamiento del realizador, algo patente en su presentación en el film junto a Boiffard, ubicados a ambos lados de una barra de bar, con una interesante y vanguardista decoración mural. En contraste con sus productos fílmicos anteriores, donde el autor americano introdujo infinidad de obras y citas autorreferenciales, éste fue un encargo donde los elementos venían dados por el contexto del rodaje.

La aproximación a la casa comienza con largas panorámicas desde el jardín, con travellings cuyo montaje no desemboca en una visión unitaria, sino fragmentada, para continuar desubicando al espectador. El Jardin d'Eau et de Lumière de Gabriel Guevrekian, era una verdadera obra plástica que el mecenas vio en la Exposition International des Arts Décoratifs de 1925, y

25 Los personajes efectúan una tirada de dados que, a juzgar por los títulos, expresa la duda entre irse o permanecer. Es una secuencia similar al pasaje de Locus Solus de Raymond Roussel, donde Noël recurre al lanzamiento de dados para decidir qué páginas abrir de un código cabalístico, para leerlo mediante una lupa.

Man Ray acompañó ésta y las siguientes escenas del viaje con un ritmo de percusión muy similar al tam-tam africano, titulado Samba Tembo, de Thurston Knudson y Augie Goupil, que intensifica esa atmósfera de aventura de la ruta, hasta llegar al lugar, anunciado por la señalética: Noailles St. Bernard Propriété et Chemin Privé. 
encargó una réplica para su mansión en Hyères. Contaba con un plan triangular, albergando zonas con cerámicas ortogonales de colores, parterres para plantas, árboles y espacios para esculturas, delimitado todo por un muro perimetral blanco, con grandes aberturas equidistantes rectangulares, que hacen del paisaje visto a través un conjunto de lienzos constituidos por la propia realidad circundante, con sus efectos variables, además de presentar una estructura en continuidad muy similar a la del celuloide. Esta especie de pinacoteca en plein air que conforman los fragmentos de realidad enmarcada, se complementa con una suerte de museo de escultura al aire libre presidido por Étoile du jour ${ }^{26}$, donde destaca La Joie de vivre (1927), una obra cubista de Jacques Lipchitz, que Man Ray filmó en un movimiento giratorio. Este recurso casi hipnótico de presentar los objetos ejecutando un movimiento circular, ya lo aplicó en sus películas anteriores para que sus producciones artísticas se manifestaran ante la cámara creando una constante en el giro, contribuyendo a la gestación de la imagen óptica que las culminaba.

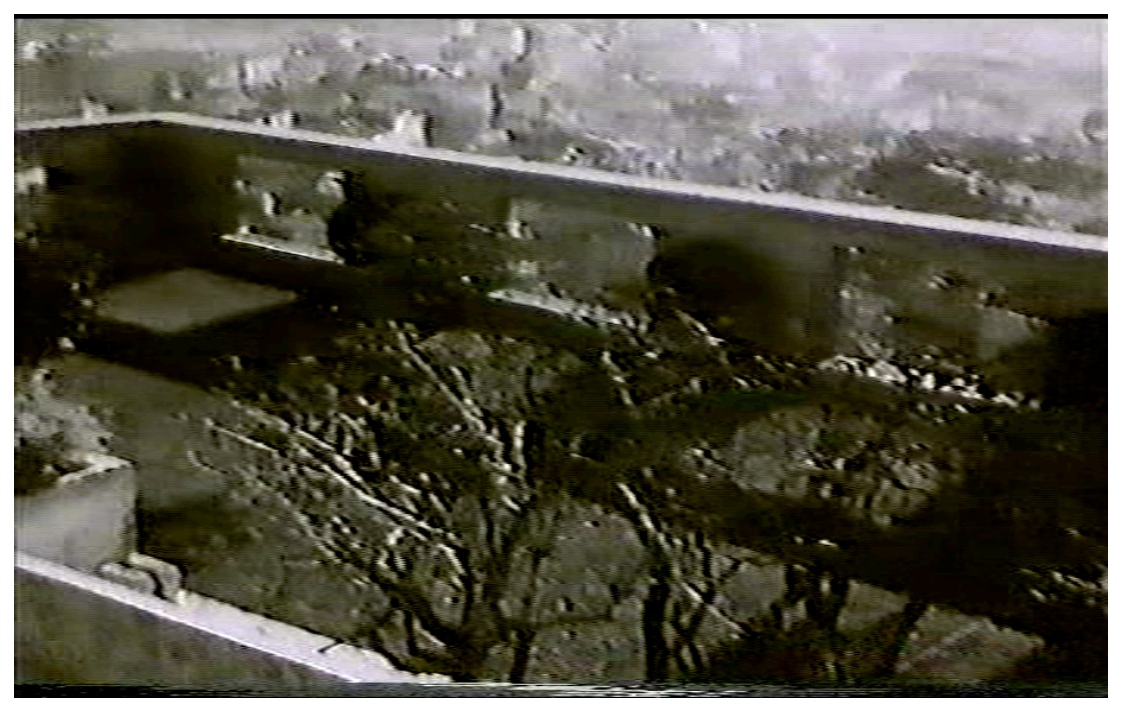

F.1 Les Mystères du château du dé. Captura de pantalla del jardín, donde se aprecia el muro con perforaciones rectangulares equidistantes.

${ }^{26}$ Estrella del día Se trata de una estrella blanca de múltiples puntas, que se inserta en la iconografía estrellada tan cara al americano, estableciendo continuidad con su anterior film, L'Étoile de mer. 


\section{Un cine de naturaleza conceptual}

Man Ray convirtió el interior de la mansión de los Noailles en un universo excepcional, como proponía Alfred Jarry con la 'Pataphysique. Para incrementar el extrañamiento, el artista incluyó una serie de perspectivas originales, colocando la cámara sobre un carro para filmar a ras del suelo, o rodando de modo inestable, figurando un recorrido errático tal como el trazado por la mirada. Este ambiente que el artista generó en la gran pantalla, tiende un puente a ese primer cine asombroso y efectista de Georges Méliès o Segundo de Chomón, que explotaron las posibilidades de la técnica cinematográfica para crear atmósferas mágicas. Man Ray hizo lo propio para aumentar el efecto de intriga, de modo que un mueble se abre por sí solo y surge un lavabo dentro, un objeto moderno entonces pero banal, que crea una situación infrecuente, magnificada mediante el lenguaje, a través del intertítulo L'Intrus (El intruso).

El director de la obra sacó partido de la banda de imagen al intercalar los componentes lingüísticos y tipográficos, de modo que el pronombre Personne (Nadie), anticipa en la pantalla un punto de inflexión que coincide con un acompañamiento musical de tono más festivo ${ }^{27}$ y un nuevo intertítulo que anuncia Les secrets de la peinture (Los secretos de la pintura). El texto hace referencia a un juego de paneles con urdimbre metálica, montados sobre raíles móviles, que en origen servían para secar la ropa y que los Noailles reutilizaron para albergar parte de su importante colección de pintura. Man Ray creó el efecto de que los paneles del artilugio se movían por sí solos al ritmo de la música, generando un baile de objetos hilarante y misterioso, en el que únicamente se muestran las partes traseras de los lienzos; de esta manera, el americano no desvela lo que ha de permanecer oculto. Pero también sugiere que la pintura no tiene secretos que revelar, pues es la mente la que ha de penetrar todos los estratos materiales e intelectuales de la pieza para gestar su discurso en torno a ella. En un tono donde late la fina ironía dadaísta, el pionero americano recalcó que lo

${ }^{27} \mathrm{El}$ tema corresponde a la Batucada de Don Alfonso, interpretada por José Morand, con instrumentos de percusión de raíz africana. 
esencial son las ideas que la obra artística es capaz de provocar; el supuesto secreto es su propio reverso.

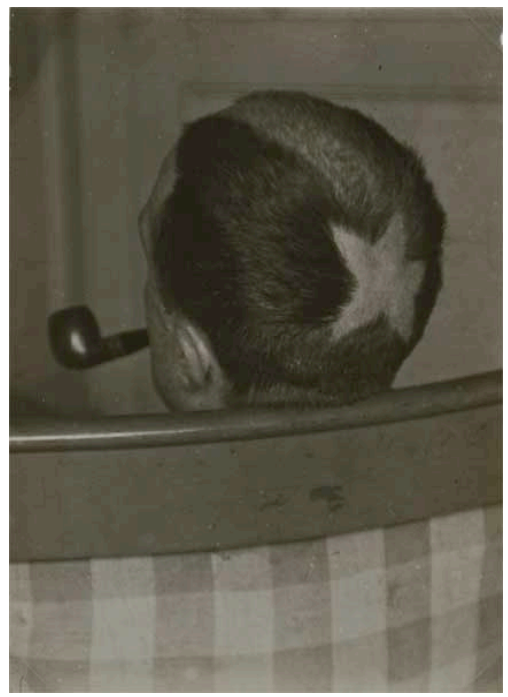

F.2 Man Ray, Tonsure (1921) Prueba en gelatina de plata. Colección privada.

Esta línea de pensamiento, que prolonga las investigaciones que llevó a cabo con Marcel Duchamp, se corresponde con la crítica subyacente en la fotografía que Man Ray tomó en Nueva York de la cabeza del francés, rapada en forma de estrella por el artista mexicano Georges de Zayas, titulada Tonsure (1921) (F2), donde la homofonía une étoile (estrella) y à toile (sobre lienzo), de manera que el lienzo sería la mente, pues las ideas toman forma en ella proyectadas como en una cámara oscura iluminada por el pensamiento.

El ritmo se va acelerando progresivamente a medida que se llega al ecuador de la película, por medio de una sucesión de intertítulos ${ }^{28}$ e imágenes que impulsan la acción. Los componentes textuales que Man Ray intercaló, incrementan la sensación de misterio, pues introducen coordenadas de tiempo y espacio sin una lógica de base donde ubicarlas, por lo tanto, lejos de aportar información, desorientan al espectador. Son reflejos, sin un anclaje real, de la concepción circular del tiempo que arrancó en la literatura de Jarry, escritor firmemente influenciado por Stéphane Mallarmé, igual que Man Ray, como se explicita en este film. Mediante la incorporación de este

${ }_{28}$ Algunos de esos textos interpelan: Où sommes nous? (¿Dónde estamos? ); Allons-nous et sortons (Vayámonos y salgamos); Ainsi vint la nuit (Así llegó la mañana); Mais quand parut le matin (Pero cuando llegó la mañana). 
procedimiento de raíz literaria, el realizador rompió con la concepción aristotélica de la acción, para adoptar la simultaneidad del proceso de pensamiento, conformando una especie de razón irracional cuya base es plenamente alucinatoria, común denominador de sus anteriores films, junto con la intencionalidad abiertamente conceptual, base de su producción integral.

\section{Improntas lúdicas}

Man Ray va a multiplicar en la segunda parte de la película los índices misteriosos de un universo intrigante (a falta de intriga): fantasmas, objetos con funciones mal definidas, perspectivas desestructuradas, juegos de luces y de sombras, indeterminaciones de la ficción, referencias mitológicas de los intertítulos. ${ }^{29}$ (Bouhours, 1995, p. 4)

El segundo bloque del film es más libre, pues los requisitos del encargo quedan satisfechos en la primera mitad. El intertítulo: Insolites, dans un coin oublié (Insólitos en un rincón olvidado), introduce a los personajes, indiferenciados por sus máscaras, pues llevan sus cabezas cubiertas por medias, negado su género, negado en ellos el tiempo pues la máscara, en el lenguaje de Jarry, hace eterno al que la porta porque es en sí una constante. Man Ray insertó una cita de Mallarmé, llevando a la pantalla el tratamiento textual en superficie característico de la versificación del literato francés, que a su vez reproduce el movimiento de una tirada de dados ${ }^{30}$. Las palabras son proyectadas desde el dispositivo cinematográfico, convirtiéndose en imagen óptica, una manifestación en la cuarta dimensión que trasciende su realidad sobre el papel.

El artista aplicó el montaje para asociar las acciones de los personajes con el azar y aportar un matiz lúdico que caracteriza todo el segundo segmento,

\footnotetext{
29 [Man Ray va multiplier dans la deuxième partie du film les indices mystérieux d'un univers intrigant (faute d'intrigue): fantômes, objets aux fonctions mal définies, perspectives déstructurantes, jeux de lumières et d'ombres, indéterminations de la fiction, références mythologiques des intertitres.]

${ }^{30}$ Un coup de dés...

...jamais n'abolira...

...LE HASARD.
} 
donde se recreó en la materialización de las presencias, los trazos y las improntas que la realidad dejaba impresas ${ }^{31}$.

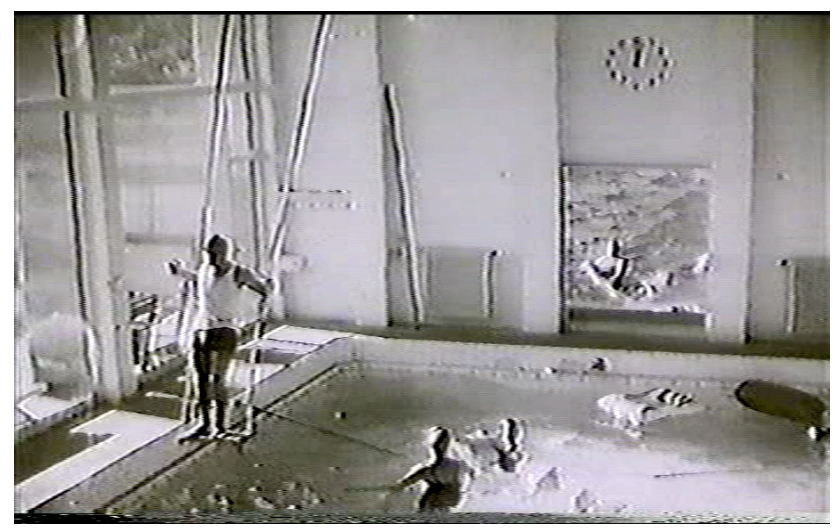

F3. Les Mystères du château du dé. Captura de pantalla de la piscina.

En esta misma línea, destaca una sucesión de escenas localizadas en la piscina $^{32}$, que permitieron a Man Ray explorar a través de la cámara el fenómeno de la percepción, filmando los elementos transparentes y reflectantes de la estancia y el juego dinámico de luces y sombras dibujado sobre distintas superficies. Los espejos, el agua y sus reflejos proyectados, o el vidrio, que abarca todo un muro del recinto acuático, se convierten aquí en sustancias para el análisis de los fenómenos de dióptrica ${ }^{33}$, actuando como pantallas de proyección en el mismo plano de la realidad ${ }^{34}$, de manera que

${ }^{31}$ En este sentido incluyó en un intertítulo la cuestión: Existe-t-il des fantômes d'action?... des fantômes de nos actions passées? Les minutes vécues ne laissent-elles pas de traces concrètes dans l'air et sur la terre? (¿Existen fantasmas de la acción?... ¿̇antasmas de nuestras acciones pasadas? Los minutos vividos ¿no dejan huellas concretas en el aire y sobre la tierra?)

${ }^{32}$ Los Noailles fueron pioneros en Francia en poseer una piscina privada climatizada en su morada, con trampolines, aparatos de gimnasia, bar, vestidor, sauna y entrenador personal. 33 La dióptrica fue codificada por Ludwig Feuerbach, como rama de la física concerniente a la refracción de la luz a través de medios de distinta densidad (aire, agua, o el propio ojo) y la transformación que esto producía en las imágenes, operando una metamorfosis en las formas de ver y en las formas de mostrar. Man Ray experimentó con este fenómeno en toda su filmografía, rodando a través de sustancias y materias transparentes, como el agua, el vidrio o prismas transparentes que alteran la visión y crean otra realidad. La luz es el agente creador, autónomo, automático y manifestado por el movimiento.

34 La primera exposición en solitario de Man Ray, "Exhibition of Drawings and Paintings by Man Ray" aconteció en noviembre de 1915 en la Daniel Gallery de Nueva York y contó con una treintena de obras expuestas. Para evitar el gasto que supondría enmarcar tantas piezas, el artista propuso una solución acorde a su línea de investigación en torno a la bidimensionalidad. Man Ray antepuso a la pared de la galería un falso muro de estopa, donde las obras eran insertas, quedando todo en el mismo plano, como sucede con la pintura al fresco. De esta manera existe continuidad entre la realidad y la obra de arte, no hay brecha entre el arte y la vida. El muro que enmarca el paisaje en el jardín de la vivienda de los 
presentan los rastros de los objetos, sin intermediarios. Este es el mismo mecanismo que se produce en la rayografía o la solarización, donde se registra por medio de la luz la huella del entorno, de los objetos manifestándose por sí mismos, hermanando fotografía y cine en el fenómeno de gestación de las imágenes. Uno de los lemas en la arquitectura de MalletStevens fue precisamente trabajar sobre esos efectos: "La forma es la intersección de la luz y de la materia"35 (Mallet-Stevens, 1996, p. 18).

\section{Citas intertextuales multimedia}

Las producciones de Man Ray para el cine están pobladas de referencias y citas biográficas, culturales y contextuales, pero sobre todo literarias. El intertítulo Les déites des eaux vives. Laissent couler leurs cheveaux (Las deidades de las aguas vivas. Dejan fluir sus cabellos), fue extraído de "Clotilde", uno de los poemas que componen Alcools (1913), de Guillaume Apollinaire. Los dos últimos versos de esa misma estrofa fueron incluidos más adelante por el cineasta: Passe il faut que tu poursuives Cette belle ombre que tu veux (Pasa, tienes que perseguir esa bella sombra que deseas), en relación con la aparición de sombras proyectadas sobre la superficie ondulante del agua. Un nuevo texto introduce el neologismo: Piscinéma, lo que aporta cierto sentido a este caligrama cinematográfico, que Man Ray ideó en una cita a su codificador en el seno de las vanguardias, Apollinaire. El director escribió las formas, liberó las sombras y dibujó poesía en la piscina, con la reverberación del agua, mediante el cine.

Destaca un elemento críptico que Man Ray incluyó con especial énfasis en esta película, y que está lleno de connotaciones. Se trata de una fórmula de maldición, que aparece tanto en la Biblia como en el Talmud, que reza: MANE-THECEL-PHARES (Mané, Tecel, Farés ${ }^{36}$ ), referente a las letras escritas con fuego por una mano misteriosa sobre el muro del salón donde

Noailles, guarda un íntimo paralelismo con las perforaciones de la estopa para acoger los lienzos y soportes de esta muestra temprana.

35 [La forme est l'intersection de la lumière et de la matière.]

${ }^{36}$ Significa: contado, pues Dios ha puesto fin al reino tras contarlo; pesado, en una balanza donde su peso es ligero; dividido: el reino se ha dividido y es entregado, anunciando la caída del Imperio. 
Baltasar celebraba su última orgía, mientras Ciro penetraba en Babilonia. Esta alusión aislada al enfrentamiento ancestral entre medos y persas, enlaza con un recurso característico de las novelas de Raymond Roussel, es decir, la inclusión de fragmentos históricos como puntos de anclaje con la realidad para, en última instancia, aumentar el grado de absurdo al intercalarlos en contextos que nada tienen que ver con un marco real. En un registro más vinculado con el universo cultural y técnico que rodeó a Man Ray, esta referencia enlaza con su biografía, dado el origen judío de su familia. En relación con el orbe literario, uno de sus autores de cabecera, indispensable para interpretar su producción, como fue Auguste Villiers de l'Isle-Adam, incorporó esta expresión en su libro, L'Ève future (1886), en los siguientes términos: "Hubiera sido tan agradable tener algunas buenas pruebas fotográficas (tomadas en el momento mismo del fenómeno)... antes, durante y después del episodio, el Mané, Tecel, Farés, del festín de Baltasar"37 (De L'Isle-Adam, 1993, p. 64). También Roussel ${ }^{38}$ utilizó estas palabras en Impressions d'Afrique (1910), en un juego lingüístico que las convertía en "manette-aiselle-phare", asociadas al faro de funcionamiento a palanca de Fogar, personaje que lograba estados de apnea que le permitían conseguir de las profundidades marinas, extraños especímenes cuya potencia luminosa los convertía en placas fotosensibles. La literatura caminaba en paralelo a los avances de la ciencia, como la fotografía, y amplificaba sus límites mediante la creatividad y la imaginación artística; Man Ray se hizo eco de este proceso en su producción integral.

Las fuentes mencionadas apelan al interés del artista por el proceso de la impresión de la realidad generando su propia huella, su potencial image, en

37 [Il nous eût été si agréable de posséder quelques bonnes épreuves photographiques (prises au moment même du phénomène) (...) avant, pendant et après l'épisode, le Mané, Thécel, Pharès, du festin de Balthazar.] Esta frase forma parte del libro I, capítulo X, titulado "Photographies de l'histoire du monde", donde se lamenta del tardío descubrimiento de la fotografía, pues se han perdido grandes momentos de los que la pintura no podrá jamás dar cuenta: "Les peintres imaginent: mais c'est la réalité positive qu'elle [la photographie] nous eût transmise." (p. 63) [Los pintores imaginan: pero es la realidad positiva lo que ella (la fotografía) nos hubiera transmitido.]

${ }_{38}^{8}$ Bouhours ya señaló el nexo entre la literatura de Roussel y la película de Man Ray.

Además, este especialista lanzó una curiosa hipótesis en torno a la posibilidad de una influencia circular de Roussel en el Grand Verre y de éste en Man Ray, por lo que quizá el contenido poético y críptico del film tenga algo que ver con los juegos de palabras de Roussel que, por vía indirecta, pasarían a Man Ray. 
términos de Dario Gamboni, como trasunto y verdadera finalidad de su plástica, en un alegato contra la representación y la mimesis. En la Torah, la fórmula trazada por la mano misteriosa deja su huella impuesta en el muro babilonio. En la obra literaria de anticipación científica de l’Isle Adam, padre del inventor ficticio Edison -evocación poética del empresario homónimo, trascendental para el mundo del cine-, las fotografías son entendidas como réalités positives, frente a la pérdida de todo referente real experimentada en la pintura. Además, un creador de machines célibataires como Roussel, trabajaba sobre impressions, trazos de realidades alternativas que quieren ser materializadas. Man Ray también ha de ser incluido en esa estela de creadores de máquinas solteras.

El realizador aplicó en el cine lo que Roussel o Jarry hicieron en literatura, es decir, el recurso a la mística y a los repertorios bíblicos y mitológicos como base verbal para provocar desplazamientos y piruetas lingüísticas, que convertían el fin último de sus producciones en la exaltación y liberación de contenidos poéticos.

\section{El juego, detonante de la plástica en movimiento. Man Ray y Henri Rousseau}

Las secuencias que constituyen casi la tercera parte de Les Mystères du château du dé, se ubican en una zona exterior habilitada para el juego, el deporte y el recreo. Allí resurgen esas presencias fantasmales de rostros velados, en un entorno insólito donde enormes balones ruedan solos y se proyectan sombras de objetos sobre el muro, generando un efecto de vibración que aporta una nueva dimensión. Los personajes juegan con diversos elementos y aparatos de gimnasia, generando imágenes dinámicas de gran plasticidad. El espacio está bañado por intensos efectos de luces y sombras. Todo el reparto está vestido con el traje que los Noailles tenían reservado para el ocio de sus invitados, que constaba de una camiseta rayada y un pantalón corto. Este atavío uniformado, que dota de una apariencia tan impersonal como reiterativa al conjunto de personajes congregados en ese entorno recreativo, a los que vemos jugando con balones, presenta una gran 
semejanza con algunos de los protagonistas de la obra de Henri Rousseau "le Douanier". El pintor francés, tan significativo para el desarrollo de la historia contemporánea del arte, fue muy relevante para el desarrollo conceptual de Man Ray en su época formativa en Estados Unidos, donde conoció sus pinturas en directo en la galería 291, propiedad de Alfred Stieglitz ${ }^{39}$, y del que llegó a poseer un lienzo ${ }^{40}$. Obras como Les joueurs de football (Los jugadores de fútbol, 1908) (F.4), presentan un parecido evidente con la estética y la ambientación del film.
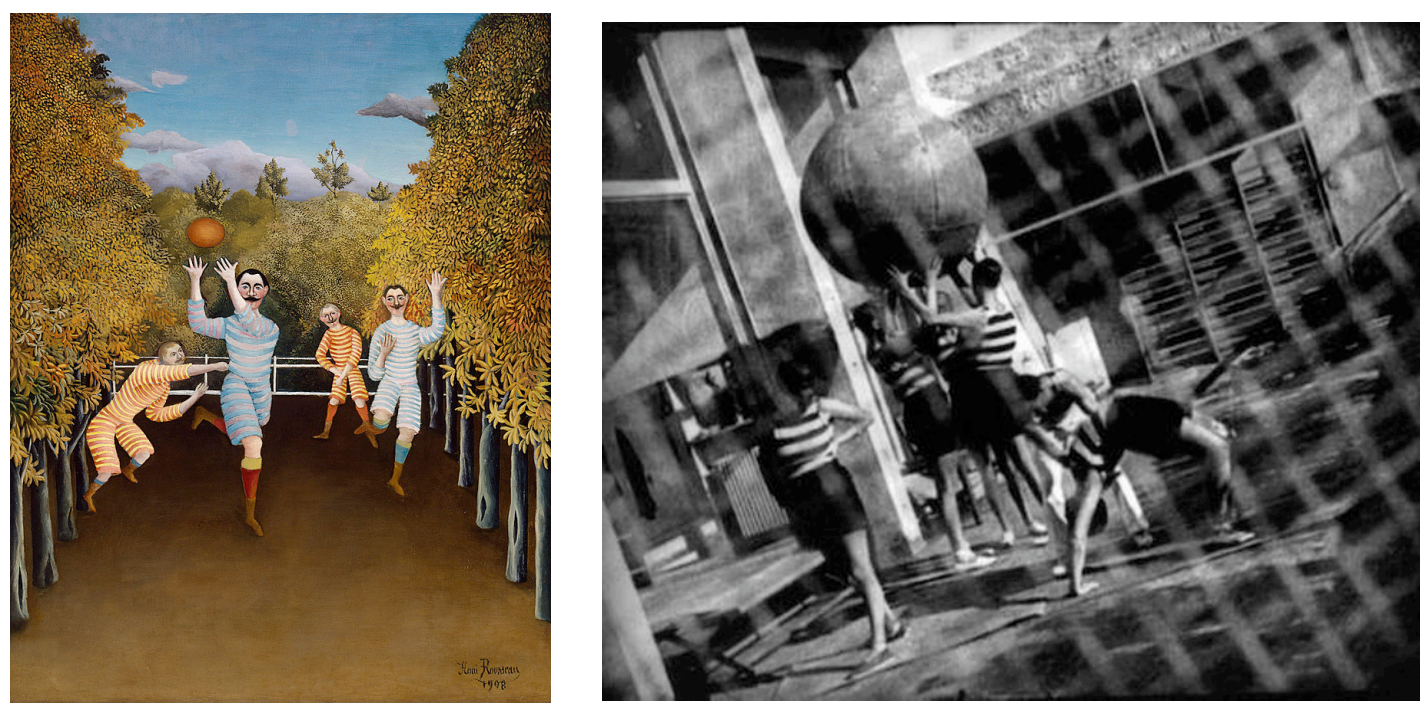

F.4 Henri Rousseau, Les joueurs de football (1908). Óleo sobre lienzo. Colección Solomon R. Guggenheim Museum, Nueva York.

F.5 Fotograma de Les Mystères du Château du Dé (1929) Archives Fonds MAN RAY 9809, Bibliothèque Kandinsky du CNAC Georges Pompidou.

La incidencia de la ruptura que supuso la plástica de Rousseau en el pensamiento estético de Man Ray se evidencia también en este film, donde se materializa el concepto de portrait-paysage (retrato-paisaje) sistematizado por el pintor francés, fusionando a las personas y a los objetos con el escenario donde se ubican. Como resultado, se conforman imágenes como

39 Entre el 18 de noviembre y el 8 de diciembre de 1910, se celebró una muestra en la galería 291 dedicada, entre otros, a las pinturas y dibujos de Henri Rousseau. Las obras expuestas procedían de una adquisición que realizó Max Weber en París, en diciembre de 1908.

$4^{\circ}$ No hemos podido determinar cuál fue esa pieza que poseyó Man Ray, pero su biógrafo Neil Baldwin alude a un lienzo de Rousseau que el americano dejó con su suministrador de materiales, Maurice Lefebvre-Foinet, al huir a Estados Unidos entre primavera y verano de 1940, escapando de la amenaza antisemita tras la ocupación de París por los nazis.

Además Arturo Schwarz recuerda que Man Ray poseía una obra del emblemático autor francés, si bien no recuerda cuál, ni tampoco el título. Información vertida en entrevista con la autora el 5-I-2015. 
unidades planas, que adquieren el aspecto de pertenecer a otra realidad distinta, donde el movimiento se opera dentro del espacio plástico, sin ilusionismo alguno. Las escenas de los lienzos de Rousseau corresponden a momentos suspendidos en el tiempo, donde la homogeneidad de los personajes entre sí parece corresponder a la expresión de las distintas fases del movimiento de uno solo, como sucedía en las experiencias fotográficas de Marey, como es connatural al cine entendido como sucesión de instantáneas. Man Ray investigó y trabajó ese efecto de creación de realidades alternativas desde las piezas que exploran la bidimensionalidad del soporte mediante el collage (The Revolving Doors, 1916-1917), o la fragmentación del movimiento (War A.D. MCMXIV, 1914), a través de la integración e impresión de lo real en los fragmentos dorados y plateados de sus collages (Chinese Theatre, 1914) o en la aerografía, e incluso en la rayografía y la solarización como huellas de un proceso intelectual, desembocando en el cine como generador de imágenes ópticas.

\section{La estructura sadiana del fotograma. Articulación de otro universo}

El tratamiento de los fotogramas fílmicos desde una concepción plástica, conecta con las estructuras planteadas por un autor trascendental para el universo literario de Man Ray, como fue el Marqués de Sade, del que emana buena parte del pensamiento del americano. El Divino Marqués integraba en su obra a los personajes con máquinas imaginadas, dentro de composiciones sistematizadas como tableaux-vivants, donde todos sus elementos están interconectados. Esta organización presenta una naturaleza similar a la del fotograma fílmico que, al percibirse fragmentado y tratado individualmente, se convierte en una suerte de objeto-fetiche imbricado en una realidad cinematográfica cuya esencia sería la de poner en marcha y hacer funcionar todo un sistema ${ }^{41}$.

${ }^{41}$ En Sade se establece una dialéctica común a gran parte de la literatura de anticipación y a las narraciones pseudocientíficas, que se reflejan en esta película. Primero aísla a los personajes y la acción, creando un vacío sin referencia, sin tiempo ni espacio existentes más 
En Las 120 jornadas de Sodoma, Sade organizó escenas equivalentes a las que ordenarán la composición fílmica, enlazando con la concepción escénica que invocaba Mallarmé y que es connatural al cine. Man Ray operó sobre estos presupuestos, creando tableaux-vivants animados por los efectos de las luces y las sombras, donde los personajes, tratados como autómatas, juegan con artefactos en una dinámica escénica donde un movimiento - el lanzamiento de los dados, el desencadenamiento del pensamiento en Man Ray, el de la perversión sexual en Sade - pone en marcha todo un programa continuo que se desarrolla en el espacio del cine, entendido como un ámbito mental donde tiene cabida lo posible proyectado al infinito, al ser convertido en una constante.

\section{Conclusión. La utopía como finalidad última hacia la transgresión de lo real}

En esencia, Man Ray ha creado aquí una utopía, entendida como una posibilidad alternativa al mundo conocido, y propone el espacio cinematográfico como el lugar idóneo para expresarla, en sustitución del medio literario utilizado por toda una estela de pensadores, artífices de nuevos universos ${ }^{42}$. Los antecedentes históricos eran abundantes, desde los gabinetes de maravillas ópticas descritos por el Padre Jean du Breuil, a las colecciones y escenografías de Louis Hesselin en la corte de Luis XIII, situados ambos en la segunda mitad del siglo XVII, donde se hablaba de estancias encantadas, espacios ilusorios, perspectivas figuradas y anamorfosis. Man Ray enlazó con esta línea de creación de ingenios en espacios utópicos mediante las potencialidades de la técnica, así como

que en la imaginación, donde todo es posible, y sigue articulando los distintos elementos que conforman ese espacio mediante una combinatoria y una sintaxis poética, en un orden necesario para que se produzca el placer para, por último, teatralizar, crear la escenografía donde se da la tautología, el sinsentido.

42 Es curioso constatar cómo la Villa Noailles guarda similitud con los escenarios descritos por Raymond Roussel y entronca con otras obras literarias proyectadas en paralelo a la evolución de la ciencia y la tecnología. Son tierras donde prima la abundancia y la electricidad anima infinidad de artilugios que producen efectos deslumbrantes, tal como sucede en esta mansión, a través de la lente de Man Ray. 
Duchamp y toda una tradición de autores de machines célibataires. De ahí que resulte complicado restringir su producción a una tendencia plástica.
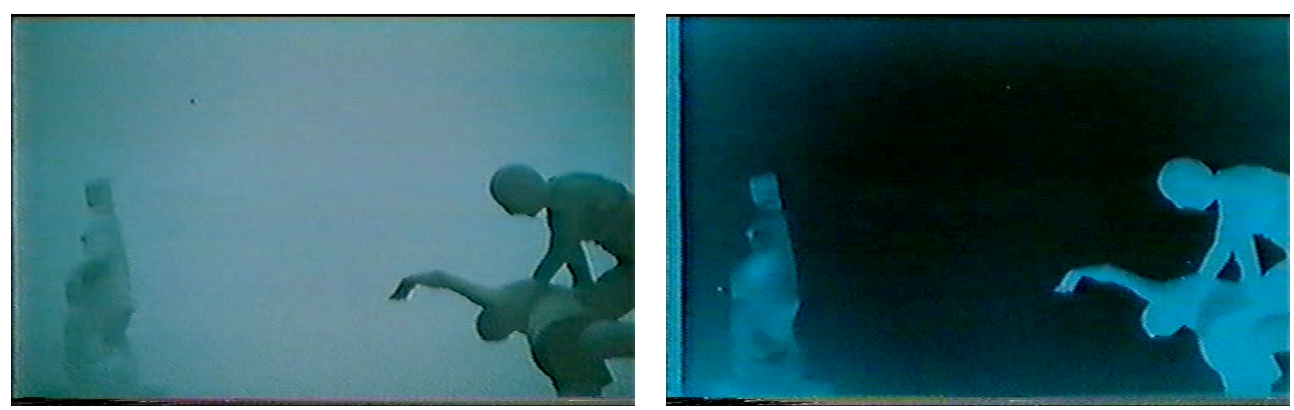

F6 y F7 Les Mystères du château du dé. Capturas de pantalla del jardín. Escena final.

El último segmento de Les Mystères du château du dé recupera la intriga e introduce dos nuevos personajes en la trama ${ }^{43}$, una pareja que funciona en pendant con los viajeros del inicio de la película, reiterando cíclicamente la aventura en el castillo. Los rostros de los individuos están cubiertos y, además, están envueltos en la niebla. Esta visión difusa conecta con el efecto producido por la profundidad de campo que las artes visuales manejan y también, en el ámbito literario, con Flatland, una novela popular en el contexto de juventud de Man Ray, en torno a la exploración de la cuarta dimensión. En este libro la acción transcurre en la niebla, que proporciona definición a los elementos sin dimensión, aportando de manera natural, fenomenológica, la profundidad de campo reservada a los dispositivos mecánicos de tratamiento de la imagen.

Si no existiese la niebla, todas las líneas parecerían indiferenciables e igualmente nítidas; (...) el resultado es que, por una observación experimental cuidadosa y constante de claridad e imprecisión relativas, somos capaces de deducir con gran exactitud la configuración del objeto observado. (Abbott, 2004, p. 41)

En los últimos compases de la película, Man Ray sorprendió con unas escenas matizadas por medio de filtros coloreados azulados y verdes, aportando una calidad pictórica. Con ellos filmó tomas panorámicas del jardín, mostrando en plano fijo una escultura antropomorfa y la pareja que

43 Se anuncia por escrito: Alors, deux voyegeurs arrivèrent dans ces lieux (Entonces dos viajeros llegaron a esos lugares), y comienza otro tema musical de cierre, esta vez Gymnopédie $N^{o}$ 2, de Erik Satie, interpretada por Stokowski. 
llega y ejecuta una serie de movimientos rítmicos, hasta adoptar una pose escultórica en la que permanecen mientras el filtro cambia de color, hasta generar su imagen en negativo. Al respecto, destaca un fragmento que su amigo y colega, Jean Cocteau, escribió en alusión a la escultura y el cine, pues retrata la idea que se ilustra en esta escena y su valor plástico inherente:

El cine ha suplantado la escultura realista. Sus figuras de mármol, sus enormes rostros pálidos, sus cuerpos con esas sombras magníficas y efectos de iluminación, toda esa humanidad inmaterial, esta inhumanidad silenciosa es la sustitución de lo que el ojo esperaba anteriormente de las estatuas. ${ }^{44}$ (Cocteau, 1998, s.p.)

En un fotógrafo profesional como era Man Ray, esa ambigüedad neblinosa cobra trascendencia pues, en primera instancia, distorsiona las formas eliminando toda definición y, en segunda instancia, logra que lo que vemos se convierta en un conjunto de impresiones, huellas, de modo que lo percibido difícilmente conformará un argumento, contribuyendo a dar forma a ese relato situado en la nada y en todas partes, pues apela a su existencia intelectual. Un nuevo boicot a la lógica y a los principios pretendidamente unívocos, que ya eclosionó en su juventud, aunando la negación constructiva del Dadá, con la revolución del anarquismo individualista.

El último de los títulos recalca: ...QUI RESTÈRENT, haciendo uso todavía del filtro azulado, para efectuar una última panorámica donde se recupera el efecto de extrañamiento. El realizador logró esta sensación rodando a la par que la cámara se desplaza sobre su propio eje, abriendo a la eternidad que aporta el giro en su continuidad, a la extensión a todo lo posible, a la indistinción de coordenadas, anuladas en la infinitud del espacio mental. El film termina en bucle, tal y como empezó, con un primer plano de las manos de madera articuladas con los dados entre ellas, siendo esta vez lanzados y decretando el final, cesa la banda sonora.

La última imagen de los dados en el film suma, según las facetas visibles, el número trece, siendo el doce para Mallarmé la cifra que indica la victoria

44 [Cinema has supplanted realistic sculpture. Its marble figures, its huge pale faces, its bodies with those magnificent shadows and lighting effects, all this immaterial humanity, this silent inhumanity is replacing what the eye formerly expected from the statues.] 
sobre el azar tras la cual, abolida la vida, solo quedaría la muerte. Man Ray parece trascender esto, manteniendo que el azar de la vida prevalece y reina sobre cualquier límite cuantitativo al que se pretenda someter. Por tanto, un lanzamiento de dados jamás anulará el azar de la vida, lo estimulará.

Ante todo, el realizador ha perseguido en este film el florecimiento de la poesía, un cine-poema que se añade a sus incursiones anteriores en el séptimo arte, imbricando imagen y texto, amplificando los límites de la obra de referencia de Mallarmé y de su exploración del absoluto ${ }^{45}$. Man Ray añadió en el film al absoluto lo posible, toda la riqueza del azar, para evitar su retracción en el tiempo y permitir así la prolongación del deseo, como promovió Jarry, como hizo Roussel, para quien: "El movimiento aparece principalmente como mecánica repetida constantemente. El tiempo es inmóvil o gira a lo loco"46 (Radrizzani, 1975, p. 149). No hay imitación de la realidad externa, todo lo que vemos es creación pura, una poética que rompe todos los esquemas de la representación. Esta dinámica liga con la del Dadá más primigenio, es una destrucción que conlleva la generación de una realidad nueva localizada en la mente como potencia, donde cabe toda utopía y cualquier proyecto de regeneración social, donde las artes tuvieron un papel de primer orden. Más particularmente, hunde sus raíces en el periodo de formación de Man Ray en el Ferrer Center de Nueva York, donde se produjo el florecimiento de su personalidad artística e ideológica y donde se pusieron las bases para la teoría artística que desarrolló a lo largo de su carrera $^{47}$.

\footnotetext{
45 En 1928, René Daumal, Roger Vailland y Robert Gilbert-Lecomte, fundaron la revista $L e$ Grand Jeu, donde analizaban la poesía de Mallarmé y su superación por la 'Pataphysique de Jarry, mediante la mecánica y lo posible. En el primer número colaboró Man Ray, con ilustraciones gráficas y fotográficas.

${ }^{46}$ [Le mouvement apparaît surtout comme mécanique constamment répetée. Le temps est immobile ou tourne à vide.]

47 El Ferrer Center fue el cuartel general donde se concitaban intelectuales relacionados con la política más radical, como Emma Goldman, Alexander Berkman o Leonard Abbott y fue un pilar de la vida cultural neoyorkina, desde que abrió sus puertas en 1911. Man Ray comenzó a frecuentar el centro desde otoño de 1912, asistiendo a las clases de arte impartidas por Robert Henri y George Bellows e involucrándose en sus publicaciones y actividades de protesta. La huella que su paso por el centro, dedicado al pedagogo español Ferrer i Guardia, fundador de la Escuela Moderna, dejó en el artista americano, fue profunda y puede rastrearse en su producción integral, su pensamiento estético y su actitud de vida.
} 
En Les Mystères du château du dé, Man Ray sugirió una utopía como prefiguración de lo posible, recogió la pulsión connatural al ser humano de convertir sus sueños -como emanaciones de lo posible-, anticipaciones placenteras e imaginaciones lúdicas, en creaciones donde una microsociedad aparte actúa según sus propias reglas, reguladas por medio del azar y desveladas por medio del cine. El ensayista Joseph Augustus Lux, afirmó:

La mayor parte de la gente sigue sin darse cuenta de que la técnica realiza nuestros ideales humanos. En lo técnico no sucede nada que ya no se haya presentado bajo la forma de un sueño, una poesía o una utopía. (Lux, 2002, p. 83).

\section{Referencias bibliograficas}

AA.VV. (1977). Le Grand Jeu. Paris: Jean-Michel Place.

Abbot, E. A. (2004). Planilandia. Una novela de muchas dimensiones. Palma de Mallorca: José J. de Olañeta

Apollinaire, G. (1998). Obra poética. Tomo I. Barcelona: 29.

Baldwin, N. (1990). Man Ray. Une vie d'artiste. Paris: Plon.

Benaïm, L. (2003). Marie Laure de Noailles. La vicomtesse du bizarre. Paris: Grasset \& Fasquelle.

Bouhours, J.-M. (1981). Les Mystères du château du dé. La légende du château du dé. En AA.VV. Man Ray, photographe (pp. 82-123). Paris: Centre Pompidou/Philippe Sers.

Bouhours, J.-M. \& De Haas, P. (1997). Man Ray, directeur du mauvais movies. Paris: Centre national d'art et de culture Georges Pompidou.

Briolle, C., Fuzibet, A. \& Monnier, G. (1999). Mallet-Stevens. La villa Noailles. Paris: Parenthèses.

Carrouges, M. (1976). Les machines célibataires. Paris: Chène.

Cocteau, J. \& Man Ray (1988). Barbette. Berlin: s. p.

Gamboni, D. (2002). Potential Images. Ambiguity and Indeterminacy in Modern Art. London: Reaktion Books.

Jarry, A. (1995). Gestes et opinions du Docteur Faustroll, pataphysicien. Paris: Gallimard. NRF.

L'Isle-Adam, V. (1993). L’ève future. Paris : Gallimard.

Lux, J. A. (2002). "Estética de la ingeniería". En Maldonado, T. (comp.), Técnica y cultura. El debate alemán entre Bismarck y Weimar (pp. 83-99). Buenos Aires: Infinito.

Mallarmé, S. (1991). Antología. Madrid: Visor. 
Mallet-Stevens, R. (1996). Le décor au Cinéma. Paris: Séguier.

Man Ray (1998). Autoportrait. Arles: Actes Sud.

Mumford, L. (1969). El mito de la máquina. Buenos Aires: Emecé.

Naumann, F. M. (2003). Conversion to Modernism. The Early Work of Man Ray. New Jersey: Rutgers University Press and Montclair Art Museum.

Puyol Loscertales, A. (2015). El periodo formativo de Man Ray. Historia cultural, técnica e ideología. Bases para su concepto estético y cinematográfico. Zaragoza: (en proceso de publicación).

Puyol Loscertales, A. (2017). "Le Retour à la raison, paradigma de film Dadá. Una presentación de la estética conceptual de Man Ray". Latente. Revista de Historia y Estética del Audiovisual, 27-44. Santa Cruz de Tenerife: Servicio de Publicaciones de la Universidad de La Laguna. https://riull.ull.es/xmlui/handle/915/2167/browse?value=Puyol+Loscertale $\mathrm{s} \% 2 \mathrm{C}+$ Ana\&type $=$ author

Radrizzani, R. (1975). Roussel explorateur de nouveaux mondes. En VV.AA., Junggesellenmaschinen. Les machines célibataires. Civitanova Marche: Alfieri, edizioni d'arte, Industrie Grafiche Editoriali S.p.A, Venezia et Harald Szeeman.

Roussel, R. (2001). Locus Solus. Paris: Gallimard.

Sade, D.A.F. de (1995). Las 120 jornadas de Sodoma. Barcelona: Tusquets.

Shattuck, R. (1991). La época de los banquetes. Orígenes de la vanguardia en Francia: de 1885 a la Primera Guerra Mundial. Madrid: Visor.

Téllez, J. L. (1985-1986). La persistencia de la memoria. (Tres Films de Man Ray). En Sánchez Biosca, V., Company, J. M. \& Pérez Perucha, J. (coords.), Contracampo. Revista de cine, $\mathrm{n}^{0}$ 40-41, año II (pp. 97-101). Valencia: Contracampo \& Instituto de Cine y Radio-Televisión.

Vaillant, O. (1995). Rationalisme et onirisme: les architectes et le cinéma. En Toulet, E. (dir.), Le cinéma au rendez-vous des arts. Paris: Bibliothèque Nationale de France. 